\title{
FAKTOR YANG MEMPENGARUHI PELAKSANAAN KETEPATAN IDENTIFIKASI PASIEN OLEH PERAWAT SEBELUM PEMBERIAN OBAT DI INSTALASI RAWAT INAP RSUD TAMIANG LAYANG
}

\author{
Septi Machelia Champaca Nursery ${ }^{1}$, Lucia Andi Chrismilasari ${ }^{2}$, Mariani $^{3}$ \\ ${ }^{1,2,3}$ STIKES Suaka Insan Banjarmasin \\ Email: septi01nursery@gmail.com
}

\begin{abstract}
Hospitals must build the right system to ensure the services provided to patients. Patient safety in hospitals begin with important step to identify patients correctly. Errors in giving an impact on the next stage of service errors such as errors in providing medicine. This study aims to identify the factors that influence the client's experience by nurses before drug administration. This type of research was quantitative with a descriptive approach, cross sectional research design, with a population of 75 nurses and a sample of 43 nurses, simple random sampling and cluster sampling were used as the sampling technique of this study. The research instrument used a questionnaire with 17 knowledge questionnaire items, 12 attitude questionnaire items, 39 safety culture questionnaire items and an observation sheet 8 statement items. Data analysis used bivariate analysis with Spearman rank test. The results of data analysis showed that safety culture had an effect on pleasure $(p=0.001 ; r=0.483)$ while knowledge $(p=0.174)$ and attitude $(p=0.372)$ had no effect on happiness before offering medicine. This study shows that safety culture has a significant influence on the timely implementation of care by nurses. A good safety culture has a positive impact on the performance of nurses in carrying out their duties to maintain patient safety.
\end{abstract}

Keywords: Patient identification, knowledge, attitude, safety culture

\begin{abstract}
Abstrak
Rumah Sakit harus membangun sistem yang tepat untuk menjamin pelayanan yang diberikan kepada pasien. Keamanan Pasien di rumah sakit dimulai dengan mengidentifikasi pasien dengan benar. Kesalahan dalam identifikasi pasien berdampak pada kesalahan pelayanan tahap selanjutnya seperti kesalahan dalam pemberian obat. Penelitian ini bertujuan untuk mengidentifikasi faktor - faktor yang mempengaruhi pelaksanaan identifikasi pasien oleh perawat sebelum pemberian obat. Jenis penelitian ini adalah kuantitatif dengan pendekatan deskriptif, desain penelitian cross sectional, dengan jumlah populasi 75 orang perawat pelaksana dan sampel 43 orang perawat pelaksana, simple random sampling dan cluster sampling digunakan sebagai teknik sampling penelitian ini. Instrumen penelitian menggunakan kuesioner dengan 17 item kuesioner pengetahuan, 12 item kuesioner sikap, 39 item kuesioner budaya keselamatan dan lembar observasi 8 item pernyataan, analisis data menggunakan analisa bivariat dengan uji Spearman rank. Hasil analisis data menunjukkan bahwa budaya keselamatan berpengaruh terhadap identifikasi pasien $(\mathrm{p}=0,001 ; \mathrm{r}=0,483)$ sedangkan pengetahuan $(\mathrm{p}=0,174)$ dan sikap $(\mathrm{p}=0,372)$ tidak berpengaruh terhadap identifikasi pasien sebelum pemberian obat. Penelitian ini menunjukkan bahwa budaya keselamatan mempunyai pengaruh signifikan terhadap pelaksanaan ketepatan identifikasi pasien oleh perawat. Budaya keselamatan yang baik berdampak positif terhadap kinerja perawat dalam melakukan tugasnya untuk menjaga keselamatan pasien.
\end{abstract}

Kata Kunci : Identifikasi pasien, pengetahuan, sikap, budaya keselamatan

\section{LATAR BELAKANG}

Keselamatan pasien rumah sakit adalah suatu sistem bagi rumah sakit untuk membuat asuhan pasien lebih aman, yang meliputi pengkajian risiko, identifikasi dan pengelolaan hal yang berhubungan dengan risiko pasien, pelaporan dan analisis insiden, kemampuan belajar dari insiden dan tindak lanjutnya serta implementasi solusi untuk meminimalkan timbulnya risiko dan mencegah terjadinya cedera yang disebabkan oleh kesalahan akibat melaksanakan suatu tindakan atau tidak mengambil tindakan yang seharusnya diambil (Permenkes RI Nomor 1691, 2011).

Sasaran keselamatan pasien wajib diterapkan di semua rumah sakit dan merupakan instrumen penilaian dalam survei akreditasi yang dilaksanakan oleh Komisi Akreditasi Rumah Sakit (KARS) menggunakan Standar Nasional 
Akreditasi Rumah Sakit (SNARS) Edisi I yang efektif digunakan sejak tanggal 01 Januari 2018. Maksud dan tujuan sasaran keselamatan pasien adalah untuk mendorong rumah sakit agar melakukan perbaikan spesifik dalam keselamatan pasien. Sistem yang baik akan berdampak pada peningkatan mutu pelayanan rumah sakit dan keselamatan pasien.

Keamanan pelayanan di rumah sakit salah satunya dimulai dari ketepatan identifikasi pasien dengan benar. Kesalahan identifikasi pasien diawal pelayanan akan berdampak pada kesalahan pelayanan pada tahap selanjutnya.

Identifikasi pasien adalah suatu sistem identifikasi kepada pasien untuk membedakan antara pasien satu dengan yang lain sehingga memperlancar atau mempermudah dalam pemberian pelayanan kepada pasien. Pasien perlu dilakukan identifikasi secara benar ketika akan diberikan obat, darah atau produk darah, pengambilan darah dan spesimen lain untuk pemeriksaan klinis atau mendapatkan tindakan medis lainnya, sehingga terhindar dari kesalahan yang mungkin dapat berakibat fatal bagi keselamatan pasien (WHO, 2007). Adapun dampak yang ditimbulkan apabila identifikasi pasien tidak dilakukan dengan benar adalah dapat menimbulkan insiden yang tidak diharapkan, salah satunya adalah salah pasien saat pemberian obat (Banyang dkk, 2013).

WHO (World Health Organitation) tahun 2004 melakukan penelitian rumah sakit di berbagai negara yaitu Amerika, Inggris, Denmark dan Australia dan ditemukan kejadian tidak diharapkan (KTD) dengan rentang 3,2\%-16,6\%. Data tersebut menjadi pemicu di berbagai negara untuk melakukan penelitian dan pengembangan sistem keselamatan pasien (Astuti, 2013).

Kasus kejadian tidak diharapkan (KTD) juga terjadi di Indonesia, dari studi yang dilakukan oleh Fakultas Kedokteran Universitas Gadjah Mada antara tahun 2001-2003, menunjukkan tingkat kesalahan pengobatan (medication error) di Indonesia mencapai angka 5,07\%, sebanyak 0,25\% berakhir fatal hingga kematian (Elrifda et al., 2011).

Pada tempat penelitian, pelaksanaan identifikasi pasien diperoleh dari hasil laporan supervisi keperawatan selama tahun 2018 dan assesor Pokja Sasaran Keselamatan Pasien (SKP) untuk pelaksanaan ketepatan identifikasi sebelum dilakukan prosedur tindakan di Instalasi rawat inap, dari laporan Pokja Sasaran Keselamatan
Pasien, terdapat satu kasus kesalahan dalam pemberian obat tahun 2017 dan satu kasus ketidaktepatan identifikasi pasien tahun 2018 dan dari hasil supervisi diketahui sekitar $40 \%$ perawat melakukan identifikasi pasien sesuai Standar Prosedur Operasional (SPO) yang telah diberlakukan di rumah sakit, sedangkan $60 \%$ tidak melakukan identifikasi sesuai SPO. Hal tersebut memungkinkan terjadinya masalah terkait penerapan sistem keselamatan pasien karena kebijakan rumah sakit dan SPO yang telah ditetapkan hanya sebatas diketahui dan tidak menjadi budaya dalam pekerjaan.

Pelaksanaan ketepatan identifikasi pasien oleh perawat sebelum pemberian obat diperlukan komitmen penuh dari seluruh elemen pelayanan yang memberikan prosedur tindakan kepada pasien. Adapun aspek - aspek yang harus dibangun dan ditingkatkan diantaranya kemampuan atau pengetahuan perawat tentang identifikasi pasien yang benar, sikap perawat dalam melaksanakan prosedur identifikasi pasien maupun sistem atau organisasi yang mendukung budaya keselamatan pasien di lingkungan kerja. Beberapa solusi telah dilakukan oleh Manajemen Rumah Sakit Umum Daerah Tamiang Layang seperti menetapkan dan melakukan sosialisasi kebijakan, panduan dan Standar Prosedur Operasional tentang pelaksanaan Ketepatan Identifikasi pasien melalui Pokja Sasaran Keselamatan Pasien kepada seluruh elemen pelaksana pelayanan yang terkait, menyelenggarakan kegiatan-kegiatan untuk meningkatkan dan mengevaluasi mutu pelayanan seperti morning report, rapat rutin dan rapat khusus internal pelayanan.

Hasil studi pendahuluan yang dilakukan di delapan ruangan rawat inap rumah sakit, melalui observasi dan wawancara pada sepuluh perawat pelaksana menunjukkan lima perawat (50\%) yang tidak melakukan identifikasi pasien pada saat pemberian obat oral dan injeksi secara benar sesuai standar prosedur operasional, sedangkan lima perawat $(50 \%)$ melaksanakan identifikasi pasien dengan benar sebelum pemberian obat.

Studi pendahuluan yang sudah dilakukan menunjukkan bahwa ada beberapa faktor yang mempengaruhi pelaksanaan ketepatan identifikasi pasien oleh perawat sebelum pemberian obat seperti pengetahuan, sikap dan budaya keselamatan. Hal ini didukung oleh d penelitian Ari Setiyajati (2014) dengan judul "Pengaruh Pengetahuan dan sikap perawat terhadap Penerapan Standar Keselamatan Pasien di Instalasi Perawatan 
Intensif RSUD Dr. Moewardi”, yang memperlihatkan bahwa pengetahuan dan sikap perawat berpengaruh terhadap penerapan standar keselamatan pasien. Semua hal ini membuat peneliti tertarik untuk melakukan penelitian tentang "Faktor yang mempengaruhi pelaksanaan ketepatan identifikasi pasien oleh perawat sebelum pemberian obat di Instalasi Rawat Inap Rumah Sakit Umum Daerah Tamiang Layang”.

\section{METODOLOGI}

Jenis penelitian ini adalah penelitian kuantitatif dengan pendekatan deskriptif. Penelitian kuantitatif adalah penelitian yang menerapkan prinsip objektifitas yang diperoleh antara lain melalui penggunaan kuesioner yang telah diuji validitas dan reliabilitasnya (Sugiyono, 2016). Penelitian ini menggunakan desain cross sectional. Populasi dari penelitian ini adalah semua perawat pelaksana di Instalasi Rawat Inap RSUD Tamiang Layang yang berjumlah 75 orang perawat. Sampel dalam penelitian ini adalah perawat pelaksana yang melaksanakan tindakan pemberian obat oral maupun injeksi, berjumlah 43 orang perawat.

Alat pengumpulan data dalam penelitian ini berupa :

1. Kuesioner pengetahuan berbentuk multiple choice diadopsi dari teori Notoadmojo mengenai pengetahuan perawat dalam melaksanakan identifikasi pasien berisi 17 pernyataan, skala ordinal dan kategori pengukuran pengetahuan baik nilai $26-34$ serta pengetahuan dikatakan kurang apabila nilai $17-25$.

2. Kuesioner sikap berbentuk check list diadopsi dari teori Anwar, berisi 12 pertanyaan, skala ordinal, kategori pengukuran sikap baik nilai 30 - 48 serta sikap dikatakan kurang apabila nilai 12 - 29.

3. Kuesioner budaya keselamatan diadopsi dari kuesioner survey AHRQ (Agency for Healthcare Research and Quality), berisi 39 pernyataan, menggunakan skala ordinal dengan kategori budaya keselamatanbaik nilai 97,6-156 dan budaya keselamatan dikatakan kurang apabila nilai $\quad 39-97,5$.

4. Lembar observasi pelaksanaan identifikasi pasien sebelum pemberian obat menggunakan lembar observasi/ checklist dengan 8 pernyataan, berdasarkan Standar Prosedur Operasional di RSUD Tamiang Layang, skala ordinal, dengan kategori identifikasi pasien tepat nilai 13 - 16 dan identifikasi pasien dikatakan tidak tepat apabila nilai 8-12.

Data-data yang diperoleh selanjutnya di analisa dengan menggunakan statistic deskriptif dan inferensial. Statistik inferensial yang dipilih adalah Spearman rank.

\section{HASIL PENELITIAN}

Penelitian ini dilakukan pada 43 partisipan yang bekerja sebagai perawat aktif di ruang rawat inap. Karakteristik partisipan dalam penelitian ini dapat dilihat pada tabel 1 di bawah ini.

Tabel 1. Distribusi Frekuensi Karakteristik Perawat berdasarkan Pendidikan Terakhir dan Lama Kerja di RSUD Tamiang Layang

\begin{tabular}{cccc}
\hline No & $\begin{array}{c}\text { Pendidikan } \\
\text { terakhir }\end{array}$ & Frekuensi & \% \\
\hline 1 & $\begin{array}{c}\text { Diploma III } \\
\text { Keperawatan } \\
\text { Sarjana } \\
\text { Keperawatan } \\
\text { Ners }\end{array}$ & 28 & 65 \\
3 & 5 & 12 \\
\hline & Jumlah & 43 & 23 \\
\hline No & Lama bekerja & Frekuensi & \% \\
\hline 1 & $\leq 5$ tahun & 15 & 35 \\
2 & $>5$ tahun & 28 & 65 \\
\hline & Jumlah & 43 & 100 \\
\hline
\end{tabular}

Tabel 1. menunjukkan sebagian besar karakteristik pendidikan terakhir perawat di Instalasi Rawat Inap RSUD Tamiang Layang adalah Diploma III Keperawatan (65\%), sebagian besar karakteristik lama bekerja perawat di Instalasi Rawat Inap RSUD Tamiang Layang adalah $\geq 5$ tahun $(65 \%)$.

Selanjutnya, partisipan berdasarkan penilaian akan pengetahuan, sikap perawat dan budaya keselamatan pasien yang dilihat dari upaya identifikasi pasien sebelum pemberian obat partisipan menunjukkan hasil yang dapat dilihat pada tabel 2. 
Tabel 2. Distribusi Frekuensi Pengetahuan Perawat, sikap dan budaya keselamatan mengenai Identifikasi Pasien Sebelum Pemberian Obat di Rumah Sakit Umum Daerah Tamiang Layang.

\begin{tabular}{|c|c|c|c|}
\hline No & $\begin{array}{c}\text { Kategori } \\
\text { pengetahuan }\end{array}$ & Frekuensi & $\%$ \\
\hline 1 & Baik & 43 & 100 \\
\hline \multirow[t]{2}{*}{2} & Kurang & 0 & 0 \\
\hline & Total & 43 & 100 \\
\hline No & $\begin{array}{c}\text { Kategori } \\
\text { sikap } \\
\end{array}$ & Frekuensi & $\%$ \\
\hline 1 & Baik & 41 & 95 \\
\hline 2 & Kurang & 2 & 5 \\
\hline Total & 43 & 100 & 100 \\
\hline No & $\begin{array}{c}\text { Kategori } \\
\text { budaya } \\
\text { keselamatan }\end{array}$ & Frekuensi & $\begin{array}{c}\text { Persentase } \\
(\%)\end{array}$ \\
\hline 1 & Baik & 27 & 63 \\
\hline 2 & Kurang & 16 & 37 \\
\hline Total & 43 & 100 & 100 \\
\hline
\end{tabular}

Tabel 2 menunjukkan sebagian besar perawat pelaksana yang diambil sebagai sampel memiliki pengetahuan yang baik, yaitu sebanyak 43 orang $(100 \%)$. Sebagian besar perawat pelaksana yang diambil sebagai sampel memiliki sikap yang baik yaitu sebanyak 41 orang (95\%), sebagian besar perawat pelaksana menunjukkan budaya keselamatan yang baik yaitu sebanyak 27 orang $(63 \%)$.
Tabel 3. Distribusi Frekuensi pelaksanaan Identifikasi Pasien oleh Perawat Sebelum Pemberian Obat di Rumah Sakit Umum Daerah Tamiang Layang.

\begin{tabular}{cccc}
\hline No & Kategori & Frekuensi & $\begin{array}{c}\text { Persentase } \\
(\%)\end{array}$ \\
\hline 1 & $\begin{array}{c}\text { Tepat } \\
\text { Tidak } \\
\text { Tepat }\end{array}$ & 14 & 33 \\
\hline & Total & 43 & 67 \\
\hline
\end{tabular}

Tabel .3 menunjukkan sebagian besar perawat pelaksana melakukan identifikasi pasien tidak tepat yaitu sebanyak 29 orang (67\%).

Tabel 4. Tabulasi Silang Analisis Hubungan antara Pengetahuan dengan Identifikasi Pasien Sebelum Pemberian Obat di Rumah Sakit Umum Daerah Tamiang Layang.

\begin{tabular}{ccccccc}
\hline & \multicolumn{6}{c}{ Identifikasi Pasien } \\
$\begin{array}{c}\text { Hubungan } \\
\text { Pengetahua } \\
\mathbf{n}\end{array}$ & \multicolumn{1}{c}{ Baik } & \multicolumn{1}{c}{ Kurang } & \multicolumn{2}{c}{ Total } \\
\cline { 2 - 7 } & $\mathbf{N}$ & $\%$ & $\mathbf{N}$ & $\%$ & $\mathbf{N}$ & $\%$ \\
\hline Baik & 43 & 100 & 0 & 0 & 43 & 0 \\
& & & & & & 0 \\
Kurang & 0 & 0 & 0 & 0 & 0 & 0 \\
Jumlah & 43 & 100 & 0 & 0 & 43 & 0 \\
& & & & & & \\
\hline
\end{tabular}

Signifikansi $(p)=0,174$

Koefisien Korelasi Spearman rho $(\mathbf{r})=\mathbf{0 , 2 1 1}$

Hasil analisa hubungan kedua variabel menggunakan uji statistik Spearman Rho menunjukkan nilai signifikansi $(\mathrm{p})=0,174$ dengan koefisien korelasi $(\mathrm{r})=0,211$. Karena nilai signifikansi $(\mathrm{p})=0,174>0,005$ dengan demikian Ha ditolak.

Koefisien korelasi $(r)=0,211$ dengan makna korelasi rendah berdasarkan pedoman kisaran angka korelasi dalam sugiyono (2015) dimana angka korelasi antara 0,20 - 0,399 maknanya korelasi rendah. 
Analisis tersebut menyimpulkan bahwa hasil penelitian menunjukkan tidak ada pengaruh yang signifikan antara pengetahuan dengan identifikasi pasien sebelum pemberian obat di Rumah Sakit Umum Daerah Tamiang Layang.

Tabel 5. Tabulasi Silang Analisis Hubungan antara Sikap dengan Identifikasi Pasien Sebelum Pemberian Obat di Rumah Sakit Umum Daerah Tamiang Layang.

\begin{tabular}{ccccccc}
\hline & \multicolumn{6}{c}{ Identifikasi Pasien } \\
\cline { 2 - 7 } $\begin{array}{c}\text { Hubungan } \\
\text { Sikap }\end{array}$ & \multicolumn{2}{c}{ Baik } & \multicolumn{1}{c}{ Kurang } & \multicolumn{2}{c}{ Total } \\
\cline { 2 - 7 } & N & $\%$ & N & $\%$ & N & $\%$ \\
\hline Baik & 41 & 95 & 0 & 0 & 41 & 95 \\
Kurang & 2 & 5 & 0 & 0 & 2 & 5 \\
Jumlah & 43 & 100 & 0 & 0 & 43 & 100 \\
\hline
\end{tabular}

Signifikansi $(\mathbf{p})=0,372$

Koefisien Korelasi Spearman rho $(\mathbf{r})=$ $\mathbf{0 , 1 3 9}$

Hasil analisa hubungan kedua variabel menggunakan uji statistik Spearman Rho menunjukkan nilai signifikansi $(\mathrm{p})=0,372$ dengan koefisien korelasi $(\mathrm{r})=0,139$ karena nilai signifikansi $(p)=0,372>0,005$, dengan demikian Ha ditolak.

Koefisien Korelasi $(r)=0,139$ dengan makna korelasi sangat rendah berdasarkan pedoman kisaran angka korelasi dalam sugiyono (2015). dimana angka korelasi antara 0,00-0,199 maknanya korelasi sangat rendah.

Analisis yang dilakukan selanjtunya menyimpulkan bahwa tidak ada pengaruh yang signifikan antara sikap perawat dengan identifikasi pasien sebelum pemberian obat di Rumah Sakit Umum Daerah Tamiang Layang
Tabel 6. Tabulasi Silang Analisis Hubungan antara Budaya Keselamatan dengan Identifikasi Pasien Sebelum Pemberian Obat di Rumah Sakit Umum Daerah Tamiang Layang.

\begin{tabular}{|c|c|c|c|c|c|c|}
\hline \multirow{3}{*}{$\begin{array}{c}\text { Hubungan } \\
\text { Budaya } \\
\text { Keselamata } \\
\text { n }\end{array}$} & \multicolumn{6}{|c|}{ Identifikasi Pasien } \\
\hline & \multicolumn{2}{|c|}{ Baik } & \multicolumn{2}{|c|}{$\begin{array}{c}\text { Kuran } \\
\text { g }\end{array}$} & \multicolumn{2}{|c|}{ Total } \\
\hline & $\mathbf{N}$ & $\%$ & $\mathbf{N}$ & $\%$ & $\mathbf{N}$ & $\%$ \\
\hline Baik & 27 & 63 & 0 & 0 & $\begin{array}{l}2 \\
7\end{array}$ & 63 \\
\hline \multirow[t]{2}{*}{ Kurang } & 16 & 37 & 0 & 0 & $\begin{array}{l}1 \\
6\end{array}$ & 37 \\
\hline & 43 & $\begin{array}{c}10 \\
0\end{array}$ & 0 & 0 & $\begin{array}{l}4 \\
3\end{array}$ & 100 \\
\hline \multicolumn{7}{|c|}{ Signifikansi $(p)=0,001$} \\
\hline
\end{tabular}

Hasil analisa hubungan kedua variabel menggunakan uji statistik Spearman Rho menunjukkan nilai signifikansi $(\mathrm{p})=0,001$ dengan koefisien korelasi $(\mathrm{r})=0,483$, karena nilai signifikansi $(p)=0,001<0,005$ dengan demikian Ha diterima.

Koefisien Korelasi $(r)=0,483$ dengan makna korelasi sedang berdasarkan pedoman kisaran angka korelasi dalam sugiyono (2015) dimana angka korelasi antara 0,400-0,599 maknanya korelasi sedang.

Analisis yang dilakukan ini menyimpulkan bahwa ada pengaruh yang signifikan antara budaya keselamatan dengan ketepatan pelaksanaan identifikasi pasien sebelum pemberian obat di Rumah Sakit Umum Daerah Tamiang Layang.

\section{PEMBAHASAN}

Pada penelitian ini mayoritas perawat mempunyai pengetahuan yang baik yaitu sebanyak 43 orang (100\%). Tingginya pengetahuan perawat pelaksana dalam penelitian ini menunjukkab bahwa sebelumnya sudah mendapatkan sosialisasi dan pelatihan terkait prosedur identifikasi pasien sebelum pemberian obat. Notoatmodjo (2010) mengatakan bahwa pengetahuan merupakan suatu hasil dari tahu dan ini terjadi setelah orang melakukan penginderaan terhadap suatu objek tertentu, melalui panca indera manusia yaitu 
penglihatan, pendengaran, penciuman, rasa dan raba (Notoatmodjo, 2010). Pengetahuan atau kognitif merupakan domain penting dalam membentuk tindakan seseorang.

Pada penelitian ini, mayoritas perawat memiliki sikap dengan kategori baik yaitu 41 orang (95\%), dimana dalam membangun budaya keselamatan pasien diperlukan komitmen yang dipengaruhi oleh pengetahuan dan sikap perawat. Perawat yang memiliki pengetahuan yang baik akan standar keselamatan pasien pastinya akan memiliki sikap yang baik dalam meningkatkan mutu pelayanan kesehatan. Pengetahuan merupakan pangkal dari sikap, sedangkan sikap akan mengarah pada tindakan seseorang (Muliana, 2016). Sikap merupakan kumpulan-kumpulan komponen kognitif, afektif dan konatif yang saling berinteraksi dan memahami, merasakan dan berperilaku terhadap suatu objek (Azwar, 2015).

Budaya keselamatan pasien merupakan nilai atau keyakinan yang dianut bersama dalam suatu organisasi untuk membuat asuhan pasien lebih aman (Yulia, 2010). Mayoritas perawat pelaksana dalam penelitian ini menunjukkan budaya keselamatan yang baik yaitu 27 perawat (63\%), adapun hal yang mendukung, sehingga harus dipertahankan dan ditingkatkan adalah kerjasama antar rekan kerja. Untungnya unit kerja di rumah sakit mempunyai kerjasama yang baik dan adanya dukungan atasan dalam menciptakan suasana kerja berorientasi pada keselamatan pasien.

Hasil analisa hubungan variabel pengetahuan dan identifikasi pasien menggunakan uji statistik Spearman Rho menunjukkan nilai signifikansi (p) $=0,174$ dengan koefisien korelasi $(\mathrm{r})=0,211$. Karena nilai signifikansi $(\mathrm{p})=0,174>0,005$ dengan demikian Ha ditolak. Analisis tersebut menunjukkan hasil penelitian yaitu tidak ada pengaruh yang signifikan antara pengetahuan dengan identifikasi pasien sebelum pemberian obat di Rumah Sakit Umum Daerah Tamiang Layang.

Pengetahuan memiliki korelasi yang rendah terhadap identifikasi pasien sebelum pemberian obat, hal tersebut sejalan dengan penelitian yang dilakukan oleh Ronaldo (2017) yang berjudul "Hubungan Pengetahuan dan Safety Culture terhadap Identifikasi Pasien Sebelum Pemberian Obat di Rumah Sakit Suaka Insan Banjarmasin" dimana pengetahuan perawat mayoritas baik sebesar 61,9\%. Hasil uji Spearman Rho menunjukkan Signifikansi $(p)=0,209>0,05$ dengan demikian $\mathrm{Ha}$ ditolak artinya tidak ada hubungan antara pengetahuan dengan identifikasi pasien. hal tersebut dimungkinkan karena masih ada faktor lain yang lebih dominan seperti budaya keselamatan, motivasi, beban kerja yang tentunya memerlukan penelitian lanjutan.

Hasil analisa hubungan sikap dan identifikasi pasien menggunakan uji statistik Spearman Rho menunjukkan nilai signifikansi $(\mathrm{p})=0,372$ dengan koefisien korelasi $(\mathrm{r})=0,139$. Nilai signifikansi $(\mathrm{p})$ $=0,372>0,005$, dengan demikian Ha ditolak. Analisis ini menunjukkan bahwa tidak ada pengaruh yang signifikan antara sikap perawat dengan identifikasi pasien sebelum pemberian obat di Rumah Sakit Umum Daerah Tamiang Layang.

Perawat harus menunjukkan sikap yang positif dalam mendukung program keselamatan pasien sehingga dapat melaksanakan praktik keperawatan secara aman dan sikap yang mendukung pencegahan penularan penyakit (Cahyono, 2008). Penerapan sasaran keselamatan pasien dapat memberikan rasa aman dan nyaman kepada pasien sehingga perawat dapat melakukan tindakan keperawatan secara profesional.

Hasil analisa budaya keselamatan dan identifikasi pasien menggunakan uji statistik Spearman Rho menunjukkan nilai signifikansi (p) $=0,001$ dengan koefisien korelasi $(\mathrm{r})=0,483$. Karena nilai signifikansi $(\mathrm{p})=0,001<0,005$ dengan demikian Ha diterima. Analisis ini menunjukkan bahwa ada pengaruh yang signifikan antara budaya keselamatan dengan ketepatan pelaksanaan identifikasi pasien sebelum pemberian obat di Rumah Sakit Umum Daerah Tamiang Layang.

Dalam penelitian ini, budaya keselamatan merupakan faktor yang mempengaruhi ketepatan pelaksanaan identifikasi pasien, hal tersebut dikarenakan budaya keselamatan pasien memiliki pengaruh langsung terhadap pelaksanaan pelayanan yang bertujuan untuk menjamin keselamatan pasien.

Keselamatan pasien (Patient Safety) adalah suatu prosedur atau proses dalam suatu Rumah sakit yang memberikan pelayanan pasien yang lebih aman.

Hughes (2008) menyatakan bahwa langkah awal memperbaiki pelayanan yang berkualitas adalah keselamatan. Sedangkan kunci dari pelayanan bermutu dan aman adalah membangun budaya keselamatan pasien, dan perawat merupakan kunci dalam pengembangan mutu melalui keselamatan pasien.

Adapun tujuan program Keselamatan Pasien Rumah Sakit adalah terciptanya budaya keselamatan pasien di Rumah Sakit, meningkatnya 
akuntabilitas Rumah Sakit terhadap pasien dan masyarakat, menurunnya kejadian tidak diharapkan di Rumah Sakit dan terlaksananya program - program pencegahan sehingga tidak ada pengulangan terjadi kejadian tidak diharapkan. Untuk mencapai tujuan tersebut, Komite Keselamatan Rumah Sakit memiliki fungsi diantaranya membudayakan keselamatan pasien di lingkungan rumah sakit, melakukan upaya umum keselamatan pasien, dan meningkatkan komunikasi yang efektif.

\section{KESIMPULAN}

Berdasarkan hasil penelitian dan pembahasan yang telah diuraikan pada hasil dan pembahasan tentang Faktor yang mempengaruhi Ketepatan Identifikasi Pasien Oleh Perawat Sebelum Pemberian Obat di Instalasi Rawat Inap RSUD Tamiang Layang Tahun 2019 maka didapatkan kesimpulan sebagai berikut :

1. Pengetahuan perawat pelaksana terhadap identifikasi pasien sebelum pemberian obat di Rumah Sakit Umum Daerah Tamiang Layang mayoritas baik dengan nilai $100 \%$.

2. Sikap perawat pelaksana terhadap identifikasi pasien sebelum pemberian obat di Rumah Sakit Umum Daerah Tamiang Layang mayoritas baik dengan nilai $95 \%$.

3. Budaya keselamatan terhadap identifikasi pasien sebelum pemberian obat di Rumah Sakit Umum Daerah Tamiang Layang mayoritas baik dengan nilai $63 \%$.

4. Pelaksanaan identifikasi pasien sebelum pemberian obat pada perawat pelaksana yang bekerja di Rumah Sakit Umum Daerah Tamiang Layang tidak tepat dengan nilai $67 \%$.

5. Faktor yang paling mempengaruhi dalam pelaksanaan identifikasi pasien oleh perawat sebelum pemberian obat adalah budaya keselamatan dengan uji statistik Spearman Rho menunjukkan nilai signifikansi $(\mathrm{p})=0,001$ dengan koefisien korelasi $(\mathrm{r})=0,483$.

\section{ACKNOWLEDGMENT}

Ucapan terimakasih kepada sahabat yaitu Lucia Andi Chrismilasari, dan rekan Maria Frani serta mahasiswa terkasih Mariani atas bantuan dalam penyelesaian penelitian ini.

\section{DAFTAR PUSTAKA}

Adisasmito W,(2012). Sistem Kesehatan. Jakarta : PT. Raja Garafindo Persada.

AHRQ. (2010), Publication No. 07-E005, Rockville, MD : Agency for Healthcare Reseach and Quality Maret : 151. www.ahrq.gov, diakses tanggal 15 Maret 2019

Arikunto, S. (2010). Prosedur Penelitian Suatu Pendekatan Praktik.Jakarta : Rineka Cipta.

Azwar Saifuddin (2015). Sikap manusia teori dan pengukurannya. Edisi 2, Yogyakarta : Pustaka Belajar

Azwar Saifuddin (2009). Reliabilitas dan Validitas. Yogyakarta : Pustaka Belajar.

Astuti, Tri Puji. (2013). Analisis Penerapan Manajemen Patient Safety Dalam Rangka Peningkatan MutuPelayanan Di RS PKU Muhammadiyah Surakarta Tahun 2013. Skripsi. Universitas Muhammadiyah Surakarta.

Ariyani. (2009). Analisis Pengetahuan dan Motivasi Perawat Yang Mempengaruhi SikapMendukung Penerapan Progran Patient Safety Di RSUD Dr. Moewardi Surakarta.

Anggraeni Dewi, Hakim Lukman (2014). Evalusi Pelaksanaan Sistem Identifikasi Pasien di InstalasiRawat Inap Rumah Sakit Panti Nirmala Malang. Jurnal. Universitas Brawijaya Malang.

Banyang dkk (2013). Faktor penyebab Medication Error di RSUD Anwar Makatutu Kabupaten Bantaeng. Universitas Hasanudin Makasar.

Budiman \& Riyanto A. 2013. Kapita Selekta Kuisioner Pengetahuan Dan Sikap Dalam Penelitian Kesehatan. Jakarta: SalembaMedika

Cahyono (2012), Membangun Budaya Keselamatan Pasien dalam praktik Kedokteran. Yogyakarta : Kanisius.

Cahyono (2008), Membangun Budaya Keselamatan Pasien dalam Praktek Dengan Komisi Akreditasi Rumah Sakit. Jakarta : KARS.

Desmita (2008). Psikologi Perkembangan. Bandung : PT.Remaja Perkembangan.

Dewi, G.K. (2010). Hubungan Antara Pengetahuan dan Sikap Patient Safety PerawatInstalasi Rawat Inap di Rumah Sakit Bhayangkara Tingkat I Raden Said Sukanto. Jakarta : Fakultas Kesehatan Masyarakat Universitas Indonesia. 
Elrifda S. (2011). Budaya Patient Safety dan Karakteristik Kesalahan Pelayanan : Implikasi Kebijakan di Salah Satu Rumah Sakit di Kota Jambi. Jambi : Jurusan Keperawatan Politeknik Jambi.

El-jardali, et all. (2014). Patient Safety Cuture in a Large Teaching Hospital in Riyadh : baseline assesment, comparative analysis and opportunities for improvement. BMC Health Services Research.

Falaqy Fiky Rofiqoh. (2010) Hubungan antara pengetahuan perawat tentang patient safety danperilaku pencegahan Medication error di IGD Rumah Sakit Krakatau Medika Cilegon.

KKP-RS. (2007). Pedoman Pelaporan Keselamatan Pasien. Jakarta : KKP-RS.

Hamdani. (2007). Analisis Budaya Keselamatan Pasien (Patient Safety Culture) di Rumah Sakit Islam Jakarta. Tesis Program Pascasarjana FIK-UI.

Hidayat, AA. (2011). Metode Penelitian Keperawatan dan Teknik Analisa Data. Jakarta: EGC

Hidayat, AA. (2014). Metode Penelitian Keperawatan dan Teknik Analisa Data. Jakarta: EGC

JCI. (2012). Joint Commision International Standar Akreditasi Rumah Sakit. Edisi 4. U.S.A : Joint Commission Resources.

Kim, I. S., Park, M. J., Park, M. Y., Yoo, H., \& Choi, J. (2013). Factors Affecting the Perception ofImportance and Practice of Patient Safety Management among Hospital Employees in Korea. AsianNursing Research, 26-32.

Komisi Akreditasi Rumah Sakit (2017). Standar Nasional Akreditasi Rumah Sakit. Edisi I, Jakarta : KARS

Kemenkes RI (2017). Peraturan Menteri Kesehatan Republik Indonesia Nomor 40 Tahun 2017 Tentang Pengembangan Karir Profesional Perawat Klinis.

Kemenkes RI(2011). Peraturan Menteri Kesehatan Republik Indonesia Nomor 1691 Tentang Keselamatan Pasien Rumah Sakit.

Katar Y.(2012). Farmakologi Obat Penyakit Infeksi Bakteri dan Jamur. Padang : Program Studi Ilmu Keperawatan UNAND.

Kee, J. L, Hayes, E.R. dan McCuistion L.E. (2009). Pharmacology a Nursing Process Aproach (6th edition). Canada : Saunders Elsevier.
Lestari, A.S. (2009). Hubungan Tingkat Pengetahuan Perawat denganPelaksanaan Dokumentasi Proses Keperawatan. Denpasar : Skripsi Keperawatan Poltekkes Depkes.

Muliana Ana, Mappanganro Andi (2016). Hubungan Pengetahuan dan Sikap Perawat dalam Penerapaf Patient Safety Goal : Identifikasi Pasien di RumahSakit Sina YWUMI Makasar. Makasar : Progran Studi Ilmu Keperawatan Fakultas Kesehatan Masyarakat UMI.

Notoatmodjo, S. (2010). Promosi Kesehatan dan Ilmu Perilaku. Jakarta : PT. Rineke Cipta.

Notoatmodjo, S. (2010). Metodologi Penelitian Kesehatan. Jakarta : PT. Rineke Cipta.

Nursalam (2015), Metodologi Penelitian. Edisi 4, Jakarta : Salemba Medika.

Nursalam (2015), Manajemen Keperawatan. Edisi 4, Jakarta : Salemba Medika.

Nursery, Septi Machelia Champaca (2017). Pelaksanaan Enam Sasaran Keselamatan Pasien Oleh PerawatDalam Mencegah Adverse Event di Rumah Sakit. Jurnal. STIKES Suaka Insan Banjarmasin.

Potter dan Perry (2010), Fundamental of Nursing. Fundamental Keperawatan, Edisi 7. Jakarta : Salemba Medika.

Pujilestari, Agustina, Maidin Alimin, Anggaini Rini (2014). Budaya Keselamatan Pasien di Instalasi Rawat Inap RSUP Dr. Wahidin Sudirohusodo Kota Makasar. Makasar : FKM UNHAS.

Ronaldo, Ferry, C.N, Septi Machelia, Trifianingsih, Dyah (2017). Hubungan Pengetahuan danSafety Culturterhadap Pelaksanaan identifikasi pasien sebelum pemberian obat. Skripsi. STIKES Suaka Insan Banjarmasin.

Pokja SKP RSUD Tamiang Layang (2017). Panduan dan Standar Prosedur Operasional Identifikasi Pasien.

Setiawan Dony dan Prasetyo Hendro, (2010), Metodologi Penelitian Kesehatan. Jakarta : Graha Ilmu.

Setiowati, Dwi.2010, Hubungan Kepemimpinan Efektif Head Nurse dengan Penerapan BudayaKeselamatan Pasien oleh Perawat Pelaksana di RSUPN Dr. Cipto Mangunkusomo.Tesis.Fakultas Ilmu Keperawatan-UI: Depok.

Setiadi (2007). Konsep dan Penulisan Riset Keperawatan. Yogyakarta : Graha Ilmu. 
Jurnal Keperawatan Suaka Insan (JKSI) Vol. 6, No. 1, Juni 2021

Setiyajati Ari (2014). Pengaruh pengetahuan dan sikap perawat terhadap penerapan standar keselamatan pasien di Instalasi perawatan Intensif RSUD Dr. Moewardi. Tesis. Universitas Sebelas Maret Surakarta.

Sugiyono (2012). Metode Penelitian Kuantitatif, Kualitatif Dan $R \&$ D . Bandung: Alfabeta.

Setiowati (2013). Kepemimpinan Efektif Head Nurse meningkatkan penerapan budaya keselamatan pasien oleh perawat pelaksana di RSUPN Dr. Cipto Mangunkusomo Jakarta : Tesis. Fakultas Ilmu Keperawatan UI.

STIKES Suaka Insan Banjarmasin (2018). Pedoman Penyusunan Proposal dan Skripsi. Banjarmasin : STIKES Suaka Insan.

Tambayong J.(2002). Farmakologi untuk Keperawatan. Jakarta : Widya Medika.

Wawan. A dan Dewi. M (2010). Teori dan Pengukuran Pengetahuan, Sikap, dan Perilaku Manusia. Yogyakarta.

Yulia, Sri.(2010). Pengaruh Pelatihan Keselamatan Pasien terhadap Pemahaman Perawat Pelaksana mengenai Penerapan Keselamatan pasien di RS Tugu Ibu. Tesis. Fakultas Ilmu Keperawatan-UI: Depok.

Yuliati Hermi (2015). Hubungan antara tingkat pengetahuan perawat tentang keselamatan pasien dengan penerapan pemberian obat di Ruang ICU RSUD Dr. Moewardi. Skripsi. STIKES Kusuma Husada Surakarta. 